\title{
O gênero no comportamento suicida: Uma leitura epidemiológica dos dados do Distrito Federal
}

Felipe de Baére. Universidade de Brasília. Valeska Zanello. Universidade de Brasília.

\section{Resumo}

O presente trabalho teve como escopo analisar o comportamento suicida a partir de dados epidemiológicos, já existentes e produzidos, envolvendo óbitos e tentativas de autoextermínio no Distrito Federal. Esses dados foram examinados sob a perspectiva de gênero, através das diferenças entre homens e mulheres, orientação sexual e identidade de gênero. Verificou-se distinções entre a frequência de óbitos e de tentativas de suicídio entre homens e mulheres, além de valores de gênero presentes nos aspectos sociodemográficos, como faixa etária, raça/cor; escolaridade, situação conjugal, entre outros elementos existentes nos documentos analisados. Em decorrência da ausência de itens presentes nos registros de óbitos e do não preenchimento de determinados campos da ficha de notificação de tentativas de autoextermínio, não foi possível examinar os dados relativos à orientação sexual e identidade de gênero, o que denota negligência com a saúde mental da população LGBT.

Palavras-chave: suicídio; gênero; epidemiologia; Distrito Federal.

\begin{abstract}
The gender in suicidal behavior: An epidemiological reading of data from the Federal District. The present study aimed to analyze suicidal behavior based on epidemiological data, already existing and produced, involving deaths and attempts at selfextermination in the Federal District of Brazil. These data were examined from the gender perspective, through the differences between men and women, sexual orientation and gender identity. Differences were observed between the frequency of deaths and suicide attempts between men and women, as well as gender values present in socio-demographic aspects, such as age, race / color; schooling, marital status, among other elements present in the records. As a result of the lack of evidence in the death registers and the non-completion of certain fields in the self-extermination notification form, it was not possible to examine data on sexual orientation and gender identity, which indicates neglect of mental health of the LGBT population.
\end{abstract}

Keywords: suicide; gender; epidemiology; Federal District.

\section{Resumen}

El género en el comportamiento suicida: Una lectura epidemiológica de los datos del Distrito Federal. Este estudio tuvo como objetivo analizar el comportamiento suicida a partir de datos epidemiológicos, ya existentes y producidos, involucrando muertes e intentos de autoexterminación en el Distrito Federal. Estos datos fueron examinados bajo la perspectiva de género, a través de las diferencias entre hombres y mujeres, orientación sexual e identidad de género. Se verificaron distinciones entre la frecuencia de muertes y de intentos de suicidio entre hombres y mujeres y valores de género presentes en los aspectos sociodemográficos, como edad, raza/color; escolaridad, situación conyugal, entre otros elementos presentes en los documentos analizados. En consecuencia de la ausencia de elementos presentes en los registros de muertes y del no llenado de determinados campos de la ficha de notificación de intentos de autoexterminación, no fue posible examinar los datos relativos a la orientación sexual e identidad de género, lo que denota negligencia con la salud mental de la población LGBT.

Palabras clave: suicidio; género; epidemiología; Distrito Federal. 
Dimensão fundamental da vida em sociedade, o gênero tem recebido diversas definições, sendo considerado uma identidade, um papel social, uma via de classificação dos corpos, entre outras possibilidades conceituais (R. Connel, 2016). Para além das perspectivas que definem o gênero como papéis sociais inscritos sobre dois tipos de corpos materialmente desiguais, Judith Butler (2015) compreende o gênero como uma performance. Em outras palavras, trata-se de um roteiro composto por atos reiterados, cuja sequência culmina na perpetuação da crença de diferenças originárias entre homens e mulheres. Desse modo, embora envolvam construções sócio-históricas, a essas distinções performáticas, por serem impulsionadas desde as fases mais arcaicas da vida, são atribuídas o estatuto de substância através de argumentos fisiológicos, com o intuito de torná-las inquestionáveis sob a legitimidade das ciências naturais (Nicholson, 2000).

Embora o peso da reafirmação das diferenças recaia sobre ambos, são as mulheres que enfrentam os maiores obstáculos em busca de garantias e direitos sociais mais equânimes (Bourdieu, 2016; Perrot, 2007). Entre os desafios em torno da desconstrução das hierarquias fundamentadas nesse conceito está a difusão das representações e auto representações do gênero nas mais variadas culturas. Ou seja, a construção do gênero não se encontra apenas em códigos comportamentais ensinados, mas em uma rede de práticas regulatórias e estratégias presentes na vida cotidiana, o que Teresa de Lauretis (1994) cunhou de "tecnologias de gênero".

O conceito de Lauretis (1994) se alinha à noção de performance de Butler (2015), ao compreender que o gênero, apenas sob o prisma da diferença sexual, na oposição universal entre homens e mulheres, encoberta sua potência conceitual, que também leva em consideração as relações subjetivas e sociais na constituição dos sujeitos. Logo, o indivíduo é gendrado, isto é, marcado pelas especificidades de gênero, por meio da linguagem e de representações culturais, o que abrange, por exemplo, as relações de raça e classe. Levar em conta as interseccionalidades (Nogueira, 2017) na constituição subjetiva é apontar para as diferenças encontradas dentro dos próprios grupos de homens e de mulheres.

Ainda que as interseccionalidades sejam acertadamente consideradas, o sentido de gênero enquanto construções sócio-históricas do binarismo masculino/ feminino não se encerra nessa compreensão. Além desta primeira acepção de gênero, há outras duas associadas às dimensões do corpo e do desejo (Zanello, 2017, 2018).
A segunda acepção envolve a correspondência entre performances de gênero e determinadas especificidades corporais. Logo, a anatomia seria o elemento fundador que estabeleceria a limitada conexão entre pênis-masculinidade e vagina-feminilidade. Neste sistema corpo-gênero encontram-se os discursos em torno da cisgeneridade e transgeneridade. A terceira está relacionada à heterossexualidade compulsória, ou seja, a compreensão de que o desejo natural e estável de um homem está direcionado à mulher, e vice-versa. Um dos argumentos que sustentam a naturalização da heterossexualidade é o entendimento do sexo como ato procriativo.

A complexidade com que o gênero, em suas diversas acepções, incide sobre a formação subjetiva, constituída em múltiplos espaços simbólicos, também pode ser compreendida através do conceito de dispositivo, proposto por Foucault (2014). Dispositivo, de acordo com o pensador francês, envolve uma rede heterogênea de "discursos, instituições, organizações arquitetônicas, decisões regulamentares, leis, medidas administrativas, enunciados científicos, proposições filosóficas, morais, filantrópicas" (p. 364). A partir dessa descrição, evidencia-se que o dispositivo não se trata de uma rede simbólica fixa e delimitada que atua sobre sujeitos, mas de uma trama em movimento, que se transforma com o tempo, em reconfigurações que oportunizam a perpetuação de seu domínio.

Em relação ao gênero neste momento histórico da sociedade ocidental, especificamente a brasileira, Zanello $(2016,2018)$ aponta para a influência de três dispositivos para se pensar a constituição subjetiva: o materno e o amoroso em relação às mulheres; o da eficácia entre os homens. Esses dispositivos devem ser pensados enquanto categorias analíticas.

O dispositivo amoroso (Zanello, 2016, 2018), pautado na dispersão do conceito de amor romântico e burguês, atua sobre a relação que as mulheres constroem consigo e umas com as outras. A subjetivação neste dispositivo perpetua a noção de que a validade identitária somente se dá quando elas são escolhidas afetivamente. Mediado pelo ideal estético branco, jovem, loiro e magro, esse dispositivo abrange o arcabouço cultural que faz com que características privilegiadas tornem certas mulheres mais aptas a serem "preferidas" do que "preteridas". Além disso, colocam o casamento como objetivo a ser alcançado, o que faz com que muitas mulheres suportem vivências de desigualdade e violência dentro do matrimônio em prol de preservação da função esposa. 
Já o dispositivo materno (Zanello, 2016, 2018) se fundamenta na justaposição entre o corpo (procriação) e a função social (maternar). A partir dessa sobreposição, mantém-se o entendimento de que a responsabilidade sobre a criação e o cuidado alheio sejam funções genuínas das mulheres. Essa ideia é difundida, sobretudo, através da naturalização do instinto materno e do amor incondicional das mães (Badinter, 1985). E mesmo que uma mulher decida por não procriar, não está isenta desse dispositivo, pois ele opera através da associação entre a mulher e a função do cuidado com o outro, nos mais variados contextos, seja familiar, seja laboral.

Por sua vez, o dispositivo da eficácia (Zanello, 2016, 2018) está relacionado ao fato de que ser homem, na cultura ocidental, fundamenta-se na virilidade laborativa e sexual. Ou seja, a masculinidade precisa ser conquistada através da demonstração de força, da sexualidade acentuada, da competitividade e da produtividade (Badinter, 1993). O reconhecimento do caráter do homem se dá pela sua capacidade de provimento e acúmulo através do trabalho e do domínio que possui sobre sua família e demais parcerias (R. W. Connel \& Messerschimidt, 2013). Ademais, umas das formas de sustentar a masculinidade hegemônica é negando quaisquer características que sejam socialmente relacionadas às mulheres (Welzer-Lang, 2001).

Esses dispositivos, assim como outras dimensões simbólicas presentes na sociedade, evidenciam a maneira capilarizada com que o gênero se embrenha na constituição subjetiva dos sujeitos. Dentre as esferas da experiência humana nas quais o gênero se faz presente está a saúde mental (Zanello, 2014). A expressão do sofrimento psíquico costuma ocorrer de forma distinta entre homens e mulheres, pois há valores e concepções aprendidas que atuam sobre a vivência e a externalização das emoções humanas (A. M. C. C Santos, 2009; Zanello \& Bukowitz, 2011).

As tecnologias de gênero, portanto, incidem sobre a formação dos sintomas no campo da saúde mental (Zanello, 2014). A taxonomia dos transtornos mentais, ao utilizar critérios descritivos cujo intuito é reforçar uma presumida neutralidade, não leva em consideração as distintas vias de manifestação das emoções, pensamentos e comportamentos influenciados pelo gênero. Consequentemente, verificam-se distinções entre homens e mulheres na epidemiologia dos transtornos mentais, que reforçam estereótipos sociais e auxiliam na perpetuação da disparidade das relações entre essas populações (Campos \& Zanello, 2016;
Zanello, 2014). Portanto, faz-se mister que as questões de gênero sejam contempladas na análise da formação dos sintomas e na atribuição dos psicodiagnósticos.

O autoextermínio, enquanto expressão limite do sofrimento psíquico, também é marcado por especificidades de gênero (Jaworski, 2010). Na década de 1990, estudos científicos que associavam o suicídio a transtornos mentais específicos passaram a ser publicados com maior frequência, bem como estatísticas sobre o aumento crescente de casos em determinados grupos (Botega, 2015). Nesse cenário, também aumentou a periodicidade das investigações em torno das diferenças encontradas no comportamento suicida de homens e mulheres, apoiadas pela maior quantidade de dados epidemiológicos disponíveis (Canetto, 1993; Canetto \& Sakinofsky, 1998; Mościcki, 1994).

No Brasil, os dados de óbitos por suicídio apontam para um crescimento contínuo nas últimas décadas. Entre 1980 e 2000, houve o aumento de $21 \%$ na taxa de mortes, sendo que os valores foram de duas a quatro vezes maiores entre os homens (Mello-Santos, Bertolotte, \& Wang, 2005). O relatório da Organização Mundial de Saúde (Organización Mundial de la Salud [OMS], 2014), que analisa os dados de mortes por suicídio em 172 nações, assinala que entre os anos 2000 e 2012 , houve um crescimento de $10,4 \%$ no Brasil, com as maiores taxas entre os homens. $O$ documento também exibe os valores absolutos de 2012, com 9.198 mortes de homens e 2.623 de mulheres. Os dados nacionais foram atualizados por um boletim epidemiológico produzido pelo Ministério da Saúde (Ministério da Saúde, 2017b), com informações relativas aos óbitos por suicídio no período de 2011 a 2015, utilizando o Sistema de Informação de Mortalidade (SIM), do DATASUS. Segundo o documento, o risco de suicídio entre os homens no intervalo analisado foi aproximadamente quatro vezes superior às mulheres.

Em relação aos números de tentativas entre os homens e as mulheres, conforme assinala o psiquiatra Neury José Botega (2015), referência em suicidologia no país, o levantamento das informações é obstaculizado em decorrência da inibida utilização dos instrumentos de notificação. Não obstante, estima-se que a frequência de tentativas de autoextermínio no mundo supere o de óbitos em, no mínimo, 10 vezes. No boletim epidemiológico (Ministério da Saúde, 2017b) supracitado, também foram apresentados os dados referentes às tentativas de suicídio no país. Com informações provenientes do Sistema de Informação de Agravo de Notificação (Sinan), 
foi observado, no intervalo entre 2011 e 2016, que o número de tentativas registradas de mulheres (69\%) superou o dobro do total de homens (31\%).

De acordo com a pesquisadora australiana Katrina Jaworski (2010), o gênero costuma ser associado ao suicídio apenas como uma interpretação posterior ao ato, sobretudo pelos dados epidemiológicos de óbitos e de tentativas. Contudo, na perspectiva da estudiosa, o próprio suicídio e os momentos que precedem o ato são gendrados, ou seja, o gênero já se encontra presente no momento de sua manifestação. Desse modo, valores de gênero são encontrados em todas as fases do comportamento suicida, desde a ideação até a tentativa, além das interpretações do fenômeno nos diferentes contextos discursivos, como no direito, na medicina e nas ciências do psiquismo.

Ainda que a epidemiologia seja importante recurso de análise das distinções da manifestação do comportamento suicida entre homens e mulheres, é preciso ir além da apreciação das evidências quantitativas restritas aos números de óbitos e de tentativas. Schrijvers, Bollen e Sabbe (2012), por exemplo, apresentam pesquisas que indicam a influência de estressores psicossociais ao longo da vida, abarcando fatores sociodemográficos e socioeconômicos. Nessa perspectiva, decorrente de padrões de gênero ensinados desde cedo, ocorrências como a separação e a viuvez estão mais relacionados ao suicídio fatal de homens, bem como a aposentadoria e o enveIhecimento. Já entre as mulheres, a maior disponibilidade para procurar tratamentos e falar sobre o histórico de saúde torna-se um fator de proteção contra a reincidência de tentativas e auxilia no aumento de registro de casos, o que confere maior visibilidade e acúmulo de informações sobre o fenômeno.

Além das diferenças entre homens e mulheres, no que tange às outras acepções de gênero, é possível relacionar o comportamento suicida às orientações sexuais dissidentes e à transgeneridade. De acordo com pesquisas na suicidologia, não ser heterossexual ou cisgênero é um fator de risco para o autoextermínio (Botega, 2015), em decorrência do sofrimento psíquico gerado pelo preconceito e a discriminação contra as dissidências sexuais e de gênero. Contudo, as informações que fundamentam essas afirmações advêm de fora do Brasil, pois ainda é incipiente o número de trabalhos que envolvem o levantamento de dados sobre o comportamento suicida LGBT no país.

Em uma pesquisa nos Estados Unidos com uma amostra de mais de 30 mil participantes, observou-se que a propensão ao suicídio entre jovens não heterossexuais foi de $20 \%$, enquanto entre jovens heterossexuais foi de 4\% (Hatzenbuehler, 2011). No mesmo país, outra investigação, de dimensão nacional, apontou que, ao longo da vida, $1,6 \%$ de pessoas cisgêneras tentaram suicídio, enquanto $41 \%$ das pessoas transgêneras atentaram contra a própria vida (Grant et al., 2010), o que indica a intensa vulnerabilidade da população trans ao suicídio e a urgência na criação de estratégias de prevenção.

A partir dos dados compartilhados, evidencia-se a relevância na elaboração de pesquisas no cenário brasileiro que alberguem os eixos temáticos: comportamento suicida, diferenças entre homens e mulheres, orientação sexual e identidade de gênero. Embora sejam importantes elementos associados à saúde mental, a maioria das pesquisas, quando se volta para essas temáticas, dá enfoque na divulgação de dados quantitativos. Os números apresentados, sem a devida análise de gênero, podem se tornar veículos de naturalização de comportamentos ao invés de instrumentos de denúncia de adversidades sociais vividas por determinadas populações. A partir das perspectivas de gênero trabalhadas no texto (Lauretis, 1994; Zanello, 2018), o presente trabalho teve como escopo analisar o comportamento suicida por meio de dados epidemiológicos, já existentes ou a serem produzidos, envolvendo óbitos e tentativas de autoextermínio no Distrito Federal (DF).

\section{Método}

Após aprovação do projeto de pesquisa no Comitê de Ética do Instituto de Ciências Humanas da Universidade de Brasília, com parecer número 2.047.212, foram disponibilizados pela Diretoria de Vigilância Epidemiológica da Secretaria de Estado de Saúde do DF (DIVEP/ SES-DF) os seguintes conteúdos referentes ao comportamento suicida do Distrito Federal:

1. Dados do Sistema de Informação de Mortalidade (SIM). Tabulação de dados, sem identificações, de óbitos por suicídio no Distrito Federal, entre os anos de 2010 e 2016, com as seguintes informações: Regiões Administrativas, sexo, idade, raça/cor, situação conjugal, escolaridade, ocupação, local de ocorrência do óbito e tipo de suicídio pelo CID-10.

2. Dados do Sistema de Informação de Agravos de Notificação (Sinan). A base de dados, sem identificações, das fichas de Notificação de Violência Interpessoal e Autoprovocada pro- 
duzidas no Distrito Federal, entre os anos de 2010 e 2016, para realizar o levantamento de informações de tentativa de suicídio do Distrito Federal neste intervalo.

A solicitação da base de dados para as tentativas de autoextermínio, ao contrário do que ocorreu com os óbitos, cujo requerimento envolveu a tabulação de dados específicos, deu-se por dois motivos. Inicialmente, era necessária a realização de uma triagem de todas as fichas de Notificação de Violência Interpessoal e Autoprovocada produzidas no DF no intervalo selecionado, levantadas até o momento da solicitação, para identificar quais delas se tratavam de tentativas de autoextermínio. Além disso, nas versões antigas desses documentos, que vigeram até 2015, como não havia o elemento "tentativas de suicídio" no campo da tipologia da violência, era recorrente o seu registro em diferentes espaços, como nos campos "meio de agressão" e "observações adicionais". Portanto, ainda que estejam presentes no documento o item relacionado à natureza da lesão (interpessoal ou autoprovocada) e o campo da tipologia da violência perpetrada, na qual pode ser incluída a tentativa de suicídio, em muitas fichas de notificação, a sinalização do autoextermínio constava somente no item das observações adicionais, espaço ao final do documento disponível para a inclusão de informações complementares.

Entre maio e julho de 2017, foram analisadas 15.635 fichas de Notificação de Violência Interpessoal e Autoprovocada produzidas no DF entre os anos de 2010 e 2016. Por fim, identificou-se que 1.218 documentos se tratavam de tentativas de autoextermínio. A partir daí, as fichas foram separadas pela categoria sexo e, posteriormente, por ano. Os conteúdos foram examinados sob a perspectiva de gênero a partir das três acepções (Zanello, 2017) e foram comparados tanto dentro do binarismo mulher e homem, quanto em sua relação com a identidade de gênero e a orientação sexual.

No intervalo entre 2010 e 2016 foi observada ampla discrepância de frequências entre os anos: 10 fichas em 2010, 51 em 2011, 98 em 2012, 135 em 2013, 164 em 2014, 374 em 2015 e 386 em 2016. Uma vez que a primeira distribuição desse documento ocorreu entre 2009/2010, é possível que profissionais que acompanhavam as ocorrências de violência desconhecessem a necessidade do preenchimento das fichas em seus anos iniciais de implementação e distribuição. Inferiu-se que tal assimetria entre os períodos adveio de um processo de familiarização com esses instrumentos por parte das instâncias que trabalham com casos de violência no DF. $\mathrm{O}$ aumento na produção das fichas também pode ter sido impulsionado por cursos ofertados pelo Núcleo de Estudos e Programas na Atenção e Vigilância em Violência (NEPAV), pertencente à DIVEP/SES-DF, para capacitação no uso das notificações.

Portanto, para viabilizar maior representatividade dos dados, optou-se pela análise dos anos 2015 e 2016. Essa etapa ocorreu entre agosto e setembro de 2017. Primeiramente, foram comparados os dados absolutos das tentativas e óbitos por suicídio. Posteriormente, as frequências de ambos foram analisadas em seus aspectos sociodemográficos.

Nas tentativas, foram observados os elementos orientação sexual, identidade de gênero, raça/cor, faixa etária, escolaridade, estado civil, reincidência, meio de agressão e Região Administrativa (RA). No campo dos óbitos, foram considerados: raça/cor, faixa etária, escolaridade, ocupação, estado civil, local de ocorrência do óbito, tipo de suicídio e RA. A partir de informações fornecidas pela DIVEP/SES-DF, também foram calculadas as taxas (por 10 mil habitantes) das RAs, presentes nas fichas de tentativas e óbitos. Todas essas informações foram calculadas e distribuídas por gênero.

Os dados epidemiológicos envolvendo o comportamento suicida de homens e mulheres do DF foram analisados sob a perspectiva das teorias de gênero (Lauretis, 1994; Zanello, 2018). A análise também abrangeu as informações sociodemográficas dessa população.

\section{Resultados e Discussão}

De acordo com os dados da Secretaria de Estado de Saúde do Distrito Federal (SES-DF), 130 pessoas tiraram suas vidas no DF em 2015 (92 homens e 38 mulheres). Em 2016, foram 146 (116 homens e 30 mulheres). De acordo com a DIVEP, esses valores encontram-se na média de óbitos anuais por suicídio de homens e mulheres no DF no período entre 2010 e 2016 , em torno de 99 homens e 32 mulheres. Em relação às tentativas de autoextermínio, em 2015, houve 374 casos notificados (252 mulheres e 122 homens) e, em 2016, o número aumentou para 386 (268 mulheres e 118 homens).

Tabela 1. Número de Óbitos e de Tentativas de Autoextermínio no DF nos Anos 2015 e 2016

\begin{tabular}{ccccc}
\hline & \multicolumn{2}{c}{ Homens } & \multicolumn{2}{c}{ Mulheres } \\
\cline { 2 - 5 } & 2015 & 2016 & 2015 & 2016 \\
\hline Óbitos & 92 & 116 & 38 & 30 \\
Tentativas & 122 & 118 & 252 & 268 \\
\hline
\end{tabular}


Evidencia-se, a partir dos valores mencionados, um número maior de óbitos de homens e uma preponderância de tentativas entre as mulheres. Ademais, embora as informações sobre as tentativas de suicídio entre 2010 e 2014 sejam subnotificadas, o número de casos envolvendo mulheres foi maior em todos esses anos. Esse fenômeno encontrado no Distrito Federal é conhecido na suicidologia como paradoxo de gênero do comportamento suicida e possui diversas explicações para a sua ocorrência (Canetto \& Sakinofsky, 1998).

Dentre as justificativas mais usuais para explicar o fenômeno encontra-se a teoria da letalidade (Mościcki, 1994). De acordo com essa compreensão, o maior número de suicídios entre os homens decorre do tipo de método empregado nas tentativas. Enquanto eles utilizam meios mais mortíferos, como armas de fogo, precipitação de locais elevados, elas buscam vias com maior possibilidade de salvamento, como a intoxicação por medicamentos. Além disso, o elevado consumo de álcool e outras drogas entre os homens seria catalisador de comportamentos impulsivos e violentos em momentos de sofrimento, incluindo a escolha de métodos mais letais (Möller-Leimkühler, 2003).

Embora o paradoxo de gênero seja uma realidade observada em diversas localidades, existe a possibilidade de haver subnotificações no número de tentativas entre os homens e de óbitos entre as mulheres (Canetto \& Sakinofsky, 1998). Homens costumam falar menos sobre seus estados emocionais (Zanello, 2014) e suas investidas no autoextermínio. Além disso, as tentativas malsucedidas não são registradas oficialmente por serem encaradas como fracassos pessoais e, recorrentemente, omitidas (Canetto \& Sakinofsky, 1998). Já entre as mulheres, métodos utilizados no suicídio estão sujeitos a erros de classificação em registros de óbitos, nos quais são encontrados termos como "envenenamento acidental" ou "ferimento indeterminado". Ademais, a família costuma encobrir com maior frequência o registro de mortes por autoextermínio entre mulheres em comparação aos homens (Canetto, 1993).

Em relação ao perfil sociodemográfico dos óbitos por suicídio no Distrito Federal, foram analisados os seguintes dados: RA, faixa etária, raça/cor, escolaridade, profissão e método empregado na tentativa de autoextermínio, sendo que nas RAs também foram calculadas as taxas por 10 mil habitantes. Nos registros de óbito, não constam os itens orientação sexual e identidade de gênero, o que impossibilita o levantamento de informações sobre as mortes por suicídio da população LGBT no Brasil.
$\mathrm{Na}$ atualidade, a inexistência de instrumentos governamentais que possam realizar o levantamento desses óbitos evidencia a omissão do Estado com as políticas públicas voltadas a essa população. Se o número de mortes e, principalmente, a sua causa fossem revelados, é provável que o governo brasileiro se tornasse alvo de críticas por parte de organizações de proteção aos direitos humanos no cenário nacional e internacional. $\mathrm{Na}$ atualidade, reivindicações de direitos sociais a essa população são obstaculizados por setores conservadores e religiosos da política, que impedem a aprovação de projetos de lei que visem o atendimento de demandas LGBT (Pereira, 2016; G. G. D. C Santos, 2016).

No que corresponde aos homens, as RAs com a maior frequência absoluta de óbitos por suicídio estão entre as mais habitadas do Distrito Federal, com populações superiores a 100 mil pessoas, como Taguatinga, Ceilândia e Samambaia. Por outro lado, houve locais que, apesar do menor contingente populacional, por apresentarem elevados valores de mortes por suicídio em comparação às demais regiões, possuíram as maiores taxas por 10 mil habitantes, como Riacho Fundo I (2,08 em 2015 e 2,55 em 2016) e Águas Claras (1,45 em 2015 e 1,42 em 2016). Entre as mulheres, as RAs com maior número de óbitos foram Taguatinga, Ceilândia, Águas Claras e Asa Norte, enquanto as maiores taxas por 10 mil habitantes foram encontradas no ano de 2015, na Candangolândia $(1,04)$ e Lago Norte $(1,02)$.

As faixas etárias que concentraram o maior número de óbitos por suicídio nos homens e nas mulheres foi 20-59 anos. Contudo, em comparação a elas, observou-se a frequência superior de mortes por suicídio entre os homens nas faixas 15-19 e acima de 60 anos. Esses intervalos costumam estar relacionados aos períodos da vida que precedem o ingresso no mercado de trabalho e a vivência de sua saída, ou seja, a aposentadoria, fases nas quais os sujeitos não estão plenamente inseridos nas atividades laborativas. Nesse sentido, uma vez que o dispositivo da eficácia (Zanello, 2016; Zanello, 2018), presente no processo de subjetivação dos homens, aponta para uma autovalorização mediada pela produtividade na ocupação profissional, é possível que a fragilização da saúde mental de jovens e de idosos aposentados esteja associada a não inserção no mercado de trabalho.

As informações etárias se alinharam às frequências relacionadas ao campo óbitos por suicídio e ocupação, ao apresentar estudantes (16,3\% em 2015 e $12 \%$ em 2016) e aposentados (10,8\% em 2015 e $9,4 \%$ 
em 2016) com as maiores porcentagens no grupo dos homens. No caso das mulheres, verificou-se o maior número de mortes por autoextermínio nas donas de casa ( $21 \%$ em 2015 e 10\% em 2016), enquanto essa mesma função apresentou valores nulos entre os homens, provavelmente pelo fato de essa função ser incomum nesse grupo. Cabe ressaltar que o trabalho de donas de casa, assim como os empregos domésticos em geral, associados majoritariamente às mulheres, é socialmente desqualificado e as coloca em posições de dependência financeira e de subalternidade perante os homens. A precarização da saúde mental das mulheres está entre os desdobramentos dessa realidade (Campos \& Zanello, 2016).

Em relação às maiores frequências encontradas na variável social raça/cor, enquanto o número de óbitos de mulheres autodeclaradas pardas (52\% em 2015 e $46 \%$ em 2016) foi próximo ao de mulheres brancas ( $44 \%$ em 2015 e 53\% em 2016), houve distinção mais acentuada entre os homens. O total de mortes de homens pardos (56\% em 2015 e $50 \%$ em 2016) foi superior ao de brancos (33\% em 2015 e 43\% em 2016). Conforme consta nas tabelas, os demais grupos (preta, amarela e indígena) tiveram baixas porcentagens no Distrito
Federal. Por outro lado, no caso do suicídio da população indígena, o Agenda Estratégica do Ministério da Saúde (Ministério da Saúde, 2017a) apontou que as taxas de óbitos por 100 mil habitantes dessa população, entre 2011 e 2016, foram significativamente superiores às outras raças.

No critério de apresentação de dados, cabe ressaltar que a despeito de o Instituto Brasileiro de Geografia e Estatísticas (IBGE) utilizar a distinção entre pretos e pardos na divulgação de seus censos demográficos, o Movimento Negro afirma ser mais representativo a junção desses dois grupos em um, o de negros. Isso se deve ao fato de a cor parda estar comumente associada a uma ausência de identidade racial, pois quem se autorrefere dessa cor ainda se encontra incerto sobre sua classificação racial e, possivelmente, pode estar vinculada ao ideal da branquitude (Bailey \& Telles, 2006; Silva \& Leão, 2012). No caso dos registros de óbitos, por não se tratar de uma autodeclaração, é possível haver uma tendência ao embranquecimento do morto, por parte dos profissionais de saúde. Em suma, pelo critério de raça utilizado pelo Movimento Negro, a população que mais se suicidou no DF nos dois anos analisados foi a de homens negros.

Tabela 2. Óbitos por Suicídio e Raça/Cor entre Homens e Mulheres do Distrito Federal

\begin{tabular}{|c|c|c|c|c|c|c|c|c|}
\hline \multirow[b]{2}{*}{ Raça/Cor } & \multicolumn{4}{|c|}{ Homens } & \multicolumn{4}{|c|}{ Mulheres } \\
\hline & 2015 & 2016 & $\begin{array}{c}2015 \\
\%\end{array}$ & $\begin{array}{c}2016 \\
\%\end{array}$ & 2015 & 2016 & $\begin{array}{c}2015 \\
\%\end{array}$ & $\begin{array}{c}2016 \\
\%\end{array}$ \\
\hline Branca & 31 & 50 & 33,69 & 43,10 & 17 & 16 & 44,73 & 53,33 \\
\hline Preta & 4 & 7 & 4,34 & 6,03 & 1 & 0 & 2,63 & 0 \\
\hline Amarela & 3 & 1 & 3,26 & 0,86 & 0 & 0 & 0 & 0 \\
\hline Parda & 52 & 58 & 56,52 & 50 & 20 & 14 & 52,63 & 46,66 \\
\hline Indígena & 0 & 0 & 0 & 0 & 0 & 0 & 0 & 0 \\
\hline Ignorado & 2 & 0 & 2,17 & 0 & 0 & 0 & 0 & 0 \\
\hline Total & 92 & 116 & 100 & 100 & 38 & 30 & 100 & 100 \\
\hline
\end{tabular}

Quanto à situação conjugal, foram separados três grupos: solteiro/viúvo/separado judicialmente, casado/união estável e item ignorado na ficha. No DF, o primeiro grupo teve as maiores porcentagens tanto para os homens ( $81 \%$ em 2015 e 71\% em 2016) como para as mulheres (68\% em 2015 e 73\% em 2016). Já no grupo casado/união estável os resultados encontrados foram $17 \%$ em 2015 e $28 \%$ em 2016 entre os homens; e $28 \%$ em 2015 e $26 \%$ em 2016 entre as mulheres. Esses valores estão de acordo com a literatura, que identifica taxas de suicídio quatro vezes maiores em pessoas viúvas, separadas e divorciadas em comparação às casadas. Já o risco entre os sujeitos solteiros é duas vezes maior do que os casados (Botega, 2015).

Por outro lado, pesquisas apontam que em conjugalidades assimétricas, atravessadas por cenários de desigualdade de investimento afetivo e cuidado, bem como de violências, o risco para a saúde mental se intensifica entre as mulheres (Zanello, 2018). Para os homens, estar sozinho, ser solteiro, divorciado ou viúvo constitui-se como fator de risco para a saúde mental em geral (Winmöller, 2016). Segundo Zanello (2018), isto se daria pelo fato de deixarem de receber os benefícios dos dispositivos amoroso e materno das mulheres. Por 
outro lado, estar sozinha, para as mulheres, colocaria em xeque o caráter identitário, gendrado, do dispositivo amoroso. Ou seja, levaria muitas delas a se sentirem "encalhadas"/preteridas, fracassadas como mulheres (Zanello, 2018).

Portanto, a despeito do que já foi observado em pesquisas estatísticas envolvendo os elementos "situação conjugal" e "comportamento suicida", evidenciou-se a necessidade de trabalhos que se utilizem de metodologias qualitativas, para que pessoas casadas ou em união estável que tenham manifestado o comportamento suicida possam compartilhar suas experiências minuciosamente.

No campo da escolaridade, a maior frequência de suicídio ocorreu entre os homens com 4-7 anos de escolarização, com 16\% em 2015 e 30\% em 2016. Já entre as mulheres, o número de óbitos por suicídio aumentou progressivamente quanto maior o tempo de permanência no período escolar. As mulheres com grau de instrução de 1-3 anos apresentaram as porcentagens $13 \%$ em 2015 e $10 \%$ em 2016, enquanto aquelas com mais de 12 anos de ensino apresentaram 28\% em 2015 e 43\% em 2016.

Esses dados apontam para interessantes questões contemporâneas relacionadas ao gênero. No caso dos homens, o menor tempo de escolarização dificulta o seu ingresso no mercado de trabalho e, consequentemente, a possibilidade de obtenção de êxito na virilidade laborativa. Já entre as mulheres, quanto maior o seu investimento em um projeto profissional, mais o dispositivo amoroso é colocado em uma encruzilhada de escolha, sendo que a maioria ou abre mão da vida profissional para se dedicar ao casamento e à maternidade ou busca conciliar todas essas atividades, acarretando quadros de profunda estafa e fragilização psíquica (Zanello, 2018).

Aproximadamente a metade das ocorrências de óbitos por suicídio ocorreram no domicílio, tanto para os homens quanto para as mulheres. O local com a segunda maior frequência de mortes por autoextermínio foi o hospital, também para ambos os gêneros. Em relação aos métodos utilizados, quase $50 \%$ das mortes se deram por enforcamento, tanto para os homens como para as mulheres. Contudo, foi observada diferenças de gênero em outros tipos de suicídio. As mulheres tiveram valores elevados nos óbitos por intoxicação intencional (31\% em 2015 e 20\% em 2016), enquanto a porcentagem entre os homens foi $15 \%$ em 2015 e $6 \%$ em 2016. Por outro lado, o uso de armas de fogo foi maior entre eles (12\% em 2015 e 14\% em 2016), em comparação às mulheres $(2,6 \%$ em $2015 \%$ e 3,3\% em 2016). Outro meio utilizado com expressiva frequência por ambos foi a precipitação de lugares elevados, com 5,4\% em 2015 e $12 \%$ em 2016 para os homens e 10,5\% em 2015 e $23,3 \%$ em 2016 para as mulheres.

A escolha do método demonstra que, em termos de intencionalidade, tanto os homens como as mulheres elegeram o enforcamento como método que assegura a morte na tentativa. Por outro lado, em consonância com a teoria da letalidade (Mościcki, 1994), houve maior frequência na utilização de armas de fogos pelos homens, enquanto o número de óbitos por intoxicação foi acentuado entre as mulheres.

Jaworski (2010) afirma que o prejuízo visível ao corpo gerado pelo método faz com que exista a crença de que certas tentativas sejam consideradas sérias, enquanto outras sejam tidas como busca por chamar a atenção. Armas de fogo, meio mais recorrido por homens, e a intoxicação medicamentosa, mais frequente entre as mulheres, fazem com que haja desqualificação das tentativas delas, sendo vistas como pedido de ajuda ou anseio por manipulação, com baixa intenção de morte. Já os atos de suicídio deles são vistos como graves e preocupantes, pois são mais violentos e definitivos. Políticas públicas de prevenção ao suicídio buscam reafirmar que, independentemente dos motivos envolvidos, quaisquer tentativas devem ser respeitadas e tomadas como atitudes sérias, que demandam acolhimento e acompanhamento (Associação Brasileira de Psiquiatria, 2014; Botega, 2015).

Dentre as informações sobre as tentativas de suicídio no DF presentes nas Fichas de Notificação de Violência Interpessoal e Autoprovocada, ao contrário do que ocorreu com os conteúdos relacionados aos óbitos, não foi possível analisar todos os elementos pré-selecionados. Ao longo da averiguação, constatou-se um padrão de não preenchimento de determinados dados dos documentos. Desse modo, foram calculadas apenas as taxas populacionais das RAs, bem como as porcentagens das faixas etárias e do método utilizado nas tentativas. Contudo, não foi possível apurar as informações sobre os campos escolaridade, raça/etnia, situação conjugal e reincidência, pois esses elementos tiveram expressiva ausência de preenchimentos, chegando a ultrapassar $80 \%$ de lacunas no item da escolaridade.

Ademais, embora os itens "orientação sexual", "nome social" e "identidade de gênero" constem nessas fichas de notificação de violência desde 2015, ano em 
que houve a reformulação do instrumento, identificou-se absoluta ausência de preenchimento desses conteúdos. Esse fato, em comparação com as declarações de óbitos, demonstra que a presença desses elementos no documento não garante a sua utilização.

Em valores absolutos, o número de casos de tentativas de suicídio em Planaltina foi expressivamente maior do que as demais RAs, com 41 registros em 2015 e 18 em 2016 entre os homens; e 89 em 2015 e 29 em 2016 entre as mulheres. O segundo lugar foi Taguatinga, com 16 casos em 2015 e sete em 2016 entre os homens; e 17 em 2015 e 16 em 2016 entre as mulheres. Sob outra perspectiva, em relação às taxas por 10 mil habitantes, as cidades com maior número de tentativas entre os homens foram Planaltina (4,4 em 2015 e 1,9 em 2016) e Paranoá (1,34 em 2015 e 4,6 em 2016). Entre as mulheres, as maiores taxas apareceram em Planaltina (8,9 em 2015 e 2,8 em 2016) e Itapoã (5,9 em 2015 e 7,0 em 2016).

Em relação às idades e à elevada ocorrência de tentativas, a faixa etária 15-39 anos obteve a maior frequência entre os homens e as mulheres. Embora a incidência de óbitos por suicídio seja elevada na população idosa (OMS, 2014), no que tange as tentativas, observou-se progressiva queda nas porcentagens de homens e mulheres a partir dos 40 anos.

Enquanto o método mais utilizado nos óbitos por suicídio foi o enforcamento, com maior potencial letal, o meio de autoextermínio mais recorrido nas tentativas foi a intoxicação intencional, tanto entre os homens (59,8\% em 2015 e 64\% em 2016) quanto entre as mulheres (75\% em 2015 e 76,8\% em 2016). A diferença entre os gêneros se deu no segundo método mais recorrido: enforcamento entre os homens $(9,8 \%$ em 2015 e $13 \%$ em 2016) e objeto perfurocortante entre as mulheres (6,7\% em 2015 e 6,3\% em 2016).

\section{Conclusão}

Ao analisar e produzir dados epidemiológicos sobre o comportamento suicida no Distrito Federal, o presente trabalho evidenciou o quanto é preciso aprimorar, inicialmente, a utilização das fichas Notificação de Violência Interpessoal e Autoprovocada. Por não haver, até o presente momento, a minuciosa análise dessas fichas de notificação, para o levantamento acurado das tentativas de autoextermínio no DF, torna-se mais árdua a elaboração estratégica de políticas públicas de prevenção do suicídio. Essa ação se faz ainda mais oportuna, quando se leva em consideração os gastos públicos na saúde envolvendo as tentativas (Botega, 2015). A pesquisa, nesse sentido, aponta para os caminhos e desafios de análise desses documentos, na busca pelo levantamento de dados mais fidedignos das intenções de suicídio.

As informações analisadas sob a perspectiva de gênero, em momento algum, visou a universalização dos conteúdos. Embora dados encontrados nesta pesquisa ratifiquem a expressividade de determinado fenômeno, como a presença do paradoxo de gênero do comportamento suicida, não é possível compreendê-lo como natural, genuíno. Canetto e Sakinofsky (1998), por exemplo, através do levantamento de pesquisas no cenário internacional, assinalam que as diferenças entre as tentativas e os óbitos por autoextermínio entre homens e mulheres se intensificam nos locais em que as relações de gênero são mais assimétricas. Nesse sentido, outros trabalhos têm enfatizado a relevância de observar em diferentes culturas o impacto das construções sociais de masculinidades e feminilidades nos comportamentos relacionados ao suicídio, ao invés de enfocar nas explicações hipotéticas baseadas apenas nos óbitos e tentativas (Jaworski, 2010; McKay, Milner, \& Maple, 2013; Payne, Swami, \& Stanistreet, 2008).

Nesse sentido, a pesquisa objetivou incentivar a reflexão sobre a influência das construções de gênero na saúde mental de homens e mulheres, através da manifestação do comportamento suicida. Embora dados epidemiológicos envolvendo os totais de óbitos e de tentativas tenham sido utilizados na investigação, foram os conteúdos sociodemográficos que viabilizaram maior averiguação da correspondência entre o gênero e a saúde mental. Portanto, a partir das distinções e semelhanças apontadas, busca-se demonstrar a necessidade de desconstrução de papéis sociais de gênero inflexíveis, que são fonte de sofrimentos para homens e mulheres.

A ausência de dados envolvendo a orientação sexual e a identidade de gênero foram empecilhos para a investigação do comportamento suicida relacionado a essas duas outras acepções de "gênero". Seja por não constarem nos registros de óbito seja por não serem preenchidas nas fichas de notificação das tentativas, em ambos os cenários, denota-se a ínfima atenção das políticas públicas de saúde brasileiras direcionadas às demandas da população LGBT. Se a literatura da suicidologia nacional e internacional aponta para um número superior de tentativas nessa população, é premente que se invista em mais pesquisas nesse campo e que se intensifiquem as estratégias preventivas para esse grupo. 


\section{Referências}

Associação Brasileira de Psiquiatria (2014). Suicídio: informando para prevenir. Brasília: CFM/ABP.

Badinter, E. (1985). Um amor conquistador: o mito do amor materno. Rio de Janeiro: Nova Fronteira.

Badinter, E. (1993). XY: sobre a identidade masculina. Rio de Janeiro: Nova Fronteira.

Bailey, R. S., \& Telles, E. E. (2006). Multiracial versus collective black categories. Ethnicitie, 6, 74-101. doi: 10.1177/1468796806061080

Botega, N. J. (2015). Crise suicida: avaliação e manejo. Porto Alegre: Artmed.

Bourdieu, P. (2016). A dominação masculina. 3. Rio de Janeiro: BestBolso.

Butler, J. (2015). Problemas de gênero: feminismo e subversão da identidade. 8. Rio de Janeiro: Civilização Brasileira.

Campos, I. C., \& Zanello, V. (2016). Saúde mental e gênero: o sofrimento psíquico e a invisibilidade das violências. Vivência: Revista de Antropologia, 1(48), 105-117. Recuperado de https://periodicos. ufrn.br/vivencia/article/view/11505

Canetto, S. S. (1993). She died for love and he for glory: Gender myths of suicidal behavior. OMEGA-Journal of Death and Dying, 26(1), 1-17. doi: 10.2190/74YQ-YNB8-R43R-7X4A

Canetto, S. S., \& Sakinofsky, I. (1998). The gender paradox in suicide. Suicide Life Threatening Behavior, 28(1), 1-23. doi: 10.1111/j.1943278X.1998.tb00622.x

Connel, R. (2016). Gênero em termos reais. São Paulo: nVersos.

Connel, R. W., \& Messerschimidt, J. W. (2013). Masculinidade hegemônica: repensando o conceito. Estudos Feministas, 21(1), 241-282. doi: 10.1590/S0104-026X2013000100014

Foucault, M. (2014). Microfísica do poder. 28. Rio de Janeiro: Paz \& Terra.

Grant, J. M., Mottet, L. A., Tanis, J., Herman, J. L., Harrison, J., \& Keisling, M. (2010). National transgender discrimination survey report on health and health care. Washington, DC: National Center for Transgender Equality and the National Gay and Lesbian Task Force.

Hatzenbuehler, M. L. (2011). The social environment and suicide attempts in lesbian, gay, and bisexual youth. Pediatrics, 127(5), 896-903. doi: 10.1542/peds.2010-3020

Jaworski, K. (2010). The gender-ing of suicide. Australian Feminist Studies, 25(63), 47-61. doi: 10.1080/08164640903499752

Lauretis, T. D. (1994). A tecnologia do gênero. In H. B. Holanda (Org.), Tendências e impasses: o feminismo como crítica da cultura (pp. 123-132). Rio de Janeiro: Rocco.

McKay, K. Milner, A., \& Maple, M. (2013). Women and suicide: Beyond the gender paradox. International Journal of Culture and Mental Health, 7(2), 168-178. doi: 10.1080/17542863.2013.765495

Mello-Santos, C., Bertolote, J. M., \& Wang, Y. (2005). Epidemiologia do suicídio no Brasil (1980-2000): caracterização das taxas de suicídio por idade e gênero. Revista Brasileira de Psiquiatria, 27(2), 131134. doi: 10.1590/S1516-44462005000200011

Ministério da Saúde (2017a). Agenda estratégica de prevenção do suicídio. Brasília, DF: Autor.

Ministério da Saúde (2017b). Suicídio: saber, agir e prevenir. Boletim epidemiológico. Brasília, DF: Secretaria de Vigilância em Saúde. Recuperado de http://portalarquivos.saude.gov.br/images/pdf/2017/
setembro/21/2017-025-Perfil-epidemiologico-das-tentativas-e-obitos-por-suicidio-no-Brasil-e-a-rede-de-atencao-a-saude.pdf

Möller-Leimkühler, A. M. (2003). The gender gap in suicide and premature death or: Why are men so vulnerable?. European Archives of Psychiatry and Clinical Neuroscience, 253(1), 1-8. doi: 10.1007/ s00406-003-0397-6

Mościcki, E. K. (1994). Gender differences in completed and attempted suicides. Annals of Epidemiology, 4(2), 152-158. doi: 10.1016/1047-2797(94)90062-0

Nicholson, L. (2000). Interpretando o gênero (L. F. G. Soares, Trad.). Revista Estudos Feministas, 8(2), 9-41. Recuperado de https:// periodicos.ufsc.br/index.php/ref/article/view/11917

Nogueira, C. (2017). Interseccionalidades e psicologia feminista. Salvador: Devires.

Organización Mundial de la Salud (2014). Prevención del suicídio: un imperativo global. Washington, DC: Organización Panamericana de la Salud.

Payne, S., Swami, V., \& Stanistreet, D. L. (2008). The social construction of gender and its influence on suicide: A review of the literature. Journal of Men's Health, 5(1), 23-35. doi: 10.1016/j.jomh.2007.11.002

Pereira, C. F. (2016). Notas sobre a trajetória das políticas públicas de direitos humanos LGBT no Brasil. Revista Interdisciplinar de Direitos Humanos, 4(1), 115-137. Recuperado de http://www2.faac. unesp.br/ridh/index.php/ridh/article/view/307

Perrot, M. (2007). Minha história das mulheres. São Paulo: Contexto.

Santos, A. M. C. C. (2009). Articular saúde mental e relações de gênero: dar voz aos sujeitos silenciados. Ciência e Saúde Coletiva, 14(4), 1177-1182. doi: 10.1590/S1413-81232009000400023

Santos, G. G. D. C. (2016). Movimento LGBT e partidos políticos no Brasil. Contemporânea: Revista de Sociologia da UFSCar, 6(1), 179. Recuperado de http://www.contemporanea.ufscar.br/index.php/ contemporanea/article/view/393

Schrijvers, D. L., Bollen, J., \& Sabbe, B. G. (2012). The gender paradox in suicidal behavior and its impact on the suicidal process. Journal of Affective Disorders, 138(1), 19-26. doi: 10.1016/j.jad.2011.03.050

Silva, G. M., \& Leão, L. T. S. (2012). O paradoxo da mistura. Identidades, desigualdades e percepção de discriminação entre brasileiros pardos. Revista Brasileira de Ciências Sociais, 27(80). doi: 10.1590/ S0102-69092012000300007

Welzer-Lang, D. (2001). A construção do masculino: dominação das mulheres e homofobia. Estudos Feministas, 9(2), 460-482. doi: 10.1590/S0104-026X2001000200008

Winmöller, N. (2016). Construção das masculinidades em depressão: revisão de literatura e análise de casos (Dissertação de Mestrado). Recuperado de http://repositorio.unb.br/handle/10482/21691

Zanello, V. (2014). A saúde mental sob o viés do gênero: uma releitura gendrada da epidemiologia, da semiologia e da interpretação diagnóstica. In V. Zanello \& A. P. M. Andrade (Orgs.), Saúde mental e gênero: diálogos, práticas e interdisciplinaridade (pp. 41-58). Curitiba: Appris. 
Zanello, V. (2016). Saúde mental, gênero e dispositivos. Cultura e processos de subjetivação. Curitiba: Editora Appris.

Zanello, V. (2017). Violência contra a mulher: o papel da cultura na formação de meninos e meninas. In B. Viza, M. C. Sartori, \& V. Zanello (Orgs.), Maria da Penha vai à escola: educar e prevenir e coibir a violência doméstica e familiar contra a mulher (pp. 24-38). Brasília:TJDFT.
Zanello, V. (2018). Saúde mental, gênero e dispositivos: cultura e processos de subjetivação. Curitiba: Appris.

Zanello, V., \& Bukowitz, B. (2011). Loucura e cultura: uma escuta das relações de gênero nas falas de pacientes psiquiatrizados. Labrys, Estudos Feministas, 20-21. Recuperado de https://www. labrys.net.br/labrys20/brasil/valeska.htm

Felipe de Baére, Mestre pelo Programa de Pós-Graduação em Psicologia Clínica e Cultura (PPG-PsiCC) da Universidade de Brasília (UnB), é Doutorando no Programa de Pós-Graduação em Psicologia

Clínica e Cultura (PPG PsiCC) da Universidade de Brasília (UnB).

Endereço para correspondência: Condomínio Solar de Brasília, Quadra 01, Conjunto 05, Casa 02, Brasília, DF, CEP: 71680-349. Telefone: (61) 99955-5775. E-mail: felipebaere@gmail.com

Valeska Zanello, Doutora em Psicologia Clínica pela Universidade de Brasília, Pós-Doutorado em Psicologia Clínica pela Universidade

Estadual Paulista (UNEP), é Professora Adjunta do Instituto de Psicologia da Universidade de Brasília (UnB). E-mail: valeskazanello@gmail.com

Recebido em 09.Abr.18 Revisado em 20.Jul.18 Aceito em 27.Ago.18 